\title{
Variation of motor unit size in the human extensor digitorum brevis and thenar muscles ${ }^{1}$
}

\author{
T. E. FEASBY AND W. F. BROWN \\ From the University Hospital, London, Ontario, Canada
}

SYNOPSIS One physiological method for estimating the motor unit number in a muscle depends $\frac{\text { }}{\Omega}$ on dividing into the maximum compound muscle action potential, the potential average of the first $ڤ$ few motor unit potentials excited by a motor nerve stimulus above motor threshold. To be valid, $\vec{\bullet}$

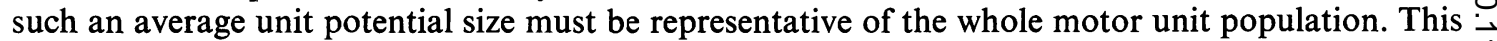
assumption may not be justified. The present study has shown that there are single motor units in $\bar{c}$ healthy and abnormal, thenar, and EDB motor unit populations, many times larger than any motor unit excited close to the motor threshold. This finding suggests that previously reported motor unit estimates may not only be an overestimate of the true motor unit population number, but have $\omega_{y}$ excluded much larger motor units with higher thresholds. Low motor unit estimates in neuropathies $\infty$ may result from a change in the order of activation of motor units with the appearance of large motor units, normally of higher threshold among the first few just above the motor threshold.

Recently a novel method for estimating the number of motor units in the extensor digitorum brevis (EDB) muscle was reported (McComas et al., 1971). Evidence of motor unit loss based on this method excited new interest in a possible neurogenic basis for muscular dystrophy. Later, a method based on similar assumptions was introduced for estimating the number of motor units in the thenar muscles by Brown (1972).

Motor unit estimates in healthy humans are approximate and should be accepted with caution. The central concept of the methods is simple:

\section{Motor Unit Estimate (MUE) =}

the compound potential sum of all the motor units evoked by a maximum motor nerve stimulus (MCP)

the average unit potential size (AUPS)

How approximate the estimates are depends on how representative the AUPS is of the whole motor unit population. Motor unit sizes often differ widely within a motor unit population

\footnotetext{
1 First presented, in part, at the 8th International Congress of Electroencephalography and Clinical Neurophysiology, Marseilles, September 1973.
}

(Wuerker et al., 1965; Eccles et al., 1968 Milner-Brown et al., 1973).

In the human, voluntary contraction recrui $\overrightarrow{6}$ large twitch units at higher thresholds than smaft twitch units (Milner-Brown et al., 1973). This evidence, and other evidence in humans and lower animals, suggests that the thenar muscles may not have a uniform population of motor unit sizes and that some motor units may be $\mathbb{\perp}$ much larger than others. It is possible that an $\overrightarrow{\vec{P}}$ AUPS based on the units with low threshold to motor nerve stimulation may not, therefore, be representative of the whole motor unit population.

Two observations prompted this study. First, in both normal subjects and those with a neuro- 3 . pathy, graded voluntary contraction does evoke motor units of successively larger potential size, some of which are many times the size of the first 0 unit potentials excited by a motor nerve stimulus and on which the AUPS is based for the MUE. Second, late responses, some of which were probably recurrent discharges of single motor ${ }^{\circ}$ units, could also be many times the size of the 0 largest motor unit potential (MUP) of the first $\mathrm{c}$ few above motor threshold. 
Difficulties in isolating single motor units during voluntary contraction, or from incremental sums beyond the first five to 20 motor units prompted us to adopt the recurrent discharge property of motoneurones to isolate motor units at higher thresholds and compare their sizes with motor units activated near threshold.

\section{METHODS}

SUBJECTS The subjects included seven normal adults (age range 20-35 years) and five patients (age range 17-49 years) with a neurological disease, including diabetic, Guillain-Barré, and porphyric neuropathies, and myotonic dystrophy and infantile hemiplegia. In all subjects, estimates were done on EDB, the thenar muscles or both.

ELECTROPHYSIOLOGICAL Methods for estimating the motor unit numbers in the EDB and the thenar muscles have been reported previously (McComas et al., 1971; Brown, 1972, 1973). Clip electrodes were adopted for the motor unit estimates in this laboratory and estimates obtained using these electrodes were almost identical with those obtained by McComas and others. The identical electrode placement was used for the study of the late response and for the motor unit estimate.

Late response-criteria for single units Late motor unit responses, invariably an $\mathrm{F}$ response, based on identical thresholds and configurations compared with units in the direct response can be readily recorded at or just above the motor threshold. A further increase in the stimulus intensity activates more motor axons but, although individual step potential increments in the thenar compound potential are recorded, direct comparison of motor units in the late and direct response is no longer possible. With a further increase in stimulus intensity, more motor axons are excited and the late response is often composed of multiple motor units.

Late discharges were accepted as single units if the following conditions were met.

1. The potentials repeated and were identical in shape and size.

2. The variation in latency was less than $100 \mu \mathrm{s}$.

3. The unit discharge appeared at a critical threshold.

4. The probability was negligible that the potential was composed of more than a single unit.

The last was based on the assumption that the probability of recurrent discharge of any moto- neurone is independent of the discharge of other motoneurones. If this is so, the probable discharge frequency of a compound potential is equal to the product of the probability of discharge of each of the component motor units-that is, $F_{\text {comp. }}=F_{1} . F_{2} \ldots$ $F_{n}$. Only late responses that met the above criteria were accepted as single units.

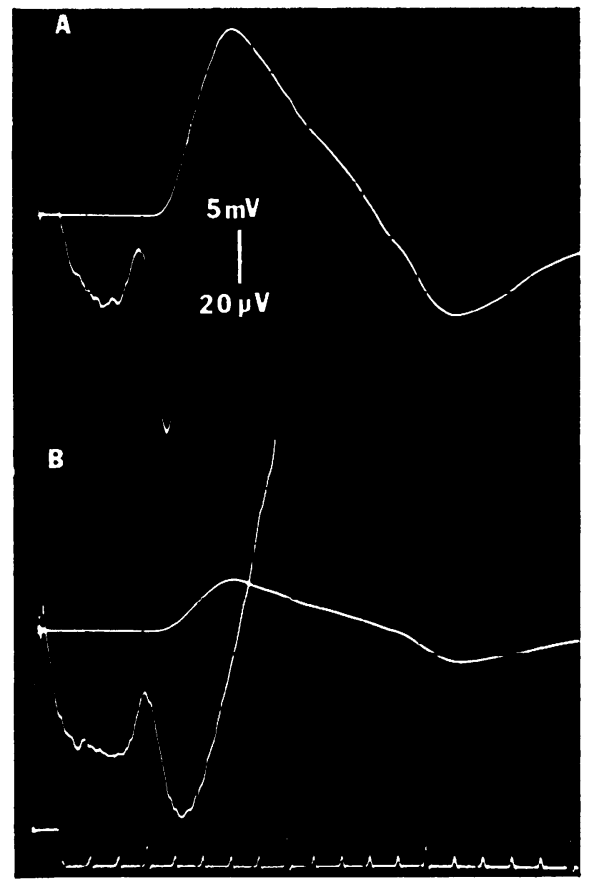

FIG. 1. The thenar compound potential and the thumb antidromic sensory potential with a stimulus supramaximal for the motor response (A) and a stimulus just maximal for the sensory potential (B) at which level the thenar potential was $30 \%$ of the maximum thenar potential.

The antidromic sensory action potentials of the first or third digit were monitored using bipolar ring electrodes. This potential was maximum when the thenar compound potential was $5-35 \%$ of its maximum size (Fig. 1). This made it unlikely that any late response motor units appearing in the mid to maximum range of the thenar compound potential were reflex $(\mathrm{H})$ responses. For the EDB, no comparable study of the sensory and motor fibres was made.

The motor nerves were stimulated at less than one 
per second. The potentials were continuously recorded on a Hewlett Packard 3690 tape recorder, which recorded the size of the direct response and the late response on independent channels. Identity of motor unit size, shape, and latency was established by a study of the delayed late responses on an expanded time base.

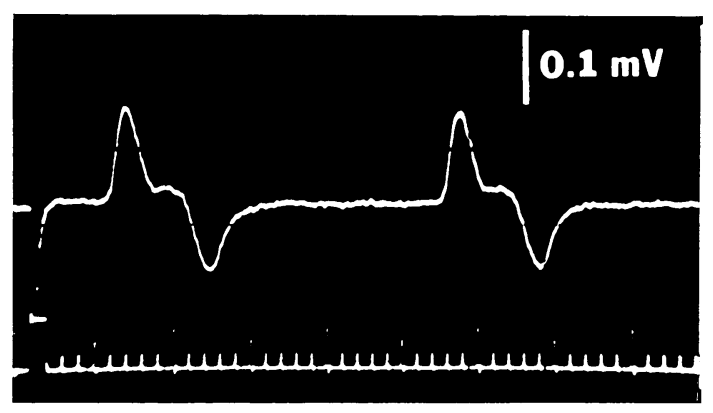

FIG. 2. The first motor unit potential in the direct response and its identical $F$ response single unit potential. The latency of the late response was $26.4 \mathrm{~ms}$.

The late responses of 100-200 successive stimuli near the motor threshold and at stimulus intensities at which the compound thenar potential was 25,50 , 75 , and $100 \%$ of its maximum size were collected. In one patient the late discharges were compared at stimulus intensities that evoked a muscle potential 33,66 , and $100 \%$ of the maximum size.

Late responses, which met the criteria for a single motor unit, were compared with each other in terms of potential size, latency, and frequency of discharge. The same late discharge single units were also of compared with the first several unit potentials on $\overline{\hat{\theta}}$ which the motor unit estimate was based and the 70 successive MUPs voluntarily evoked with graded voluntary contraction.

\section{OBSERVATIONS}

In all subjects at or just above the motor threshold, it was possible to identify single $\frac{\bar{\Xi}}{\bar{n}}$ motor unit potentials of identical shape and size $\frac{\omega}{\vec{D}}$ in the direct and late response (Fig. 2). The late 2 discharge appeared inconstantly and usually with के a low frequency (less than $5^{\circ}$ ). Beyond the first $\overrightarrow{0}$ two to four motor units (unless, as in some neuropathies, a giant unit was found) it was im- $\vec{\omega}$ possible to identify the same unit in the direct and late responses. The latencies of separate late response units varied between 23 and $32 \mathrm{~ms}$ from ${ }_{\mathcal{v}}$ the thenar muscles and 45 to $55 \mathrm{~ms}$ from thæ EDB. Each individual motor unit showed ver舟 little variation in latency (Fig. 3).

The late response is the sum of the potentia of one or more motor units. Variations in the size and latency of the response result from th\&응 inconstant firing of motor units, each of differe potential size and latency. The size of the la $\overrightarrow{0}$ discharge does increase with an increase in the $\rightarrow$ stimulus intensity, in agreement with the earlier observation of Thorne (1965). This increase in size results not from an increase in the prob-

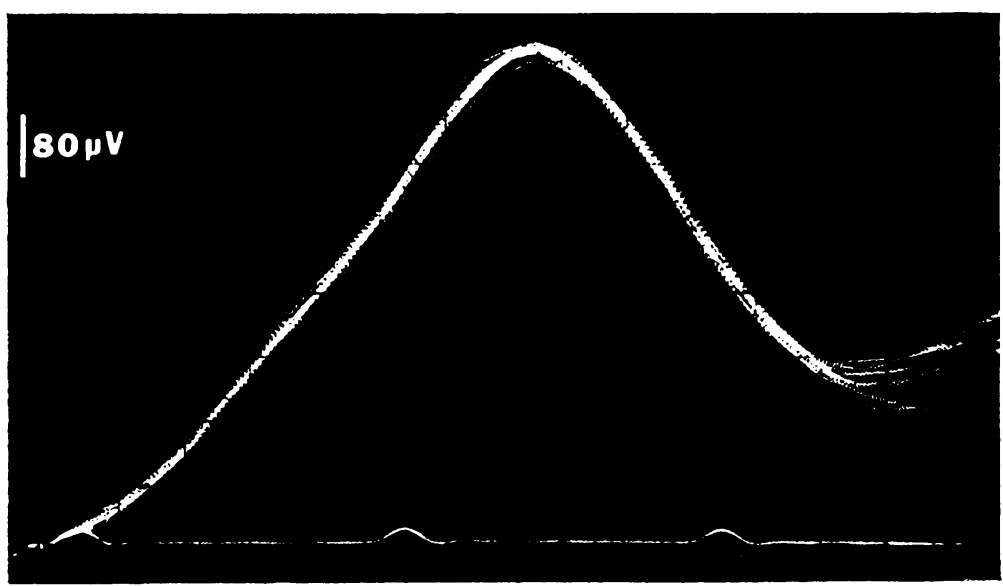

FIG. 3. Subject R.K. Fifteen superimposed late responses of a single motor unit (sweep delayed $29 \mathrm{~ms}$ ) with a latenc1 variation less than $60 \mu \mathrm{s}$. This motor unit, $600 \mu \mathrm{V}$ in size, was five times the size of the largest motor unit directly. eroked near threshold. 

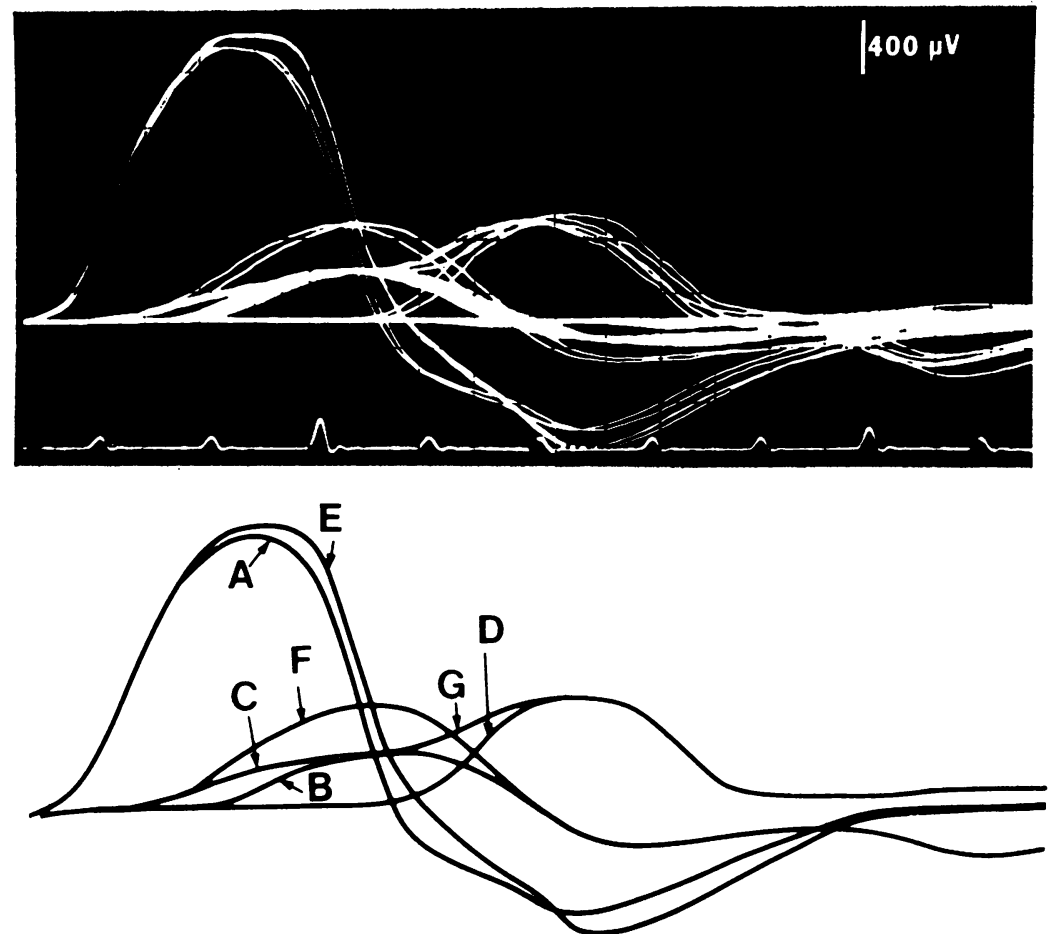

FIG. 4. Subject J.L. EDB late responses (delayed $45 \mathrm{~ms}$ ) from 200 consecutive stimuli, superimposed with an expanded time base (top), are shown with a line-drawing (bottom) to indicate the individual potentials. Potentials A, $\mathrm{B}, \mathrm{C}$, and $\mathrm{D}$ were single units and potentials $\mathrm{E}, \mathrm{F}$, and $\mathrm{G}$, were compound potentials composed of $\mathrm{A}+\mathrm{B}, \mathrm{B}+\mathrm{C}$, and $\mathrm{B}+\mathrm{D}$ respectively. The potentials occurred individually the following number of times: A-2, B-37, C-14, $\mathrm{D}-2, \mathrm{E}-3, \mathrm{~F}-2$, and $\mathrm{G}-3$. The predicted and observed discharge frequencies for the compound potentials were: $0.56 \%$ and $1.5 \%$ for E, $1.8 \%$ and $1.0 \%$ for $\mathrm{F}$, and $0.56 \%$ and $1.5 \%$ for $\mathrm{G}$. The predicted and observed frequencies did not differ significantly.

ability of discharge of any particular motor units above their critical thresholds but from the sum of more motor units and the discharge of larger motor units (Figs 4 and 6).

Higher threshold motor units in the late response are compared with the largest unit potential size and AUPS of the first few motor units just above the motor threshold in the Table. Except for the patient with porphyric neuropathy two or more higher threshold motor units larger than any motor unit potential close to the motor threshold were found in all the healthy and abnormal subjects. In fact, the largest higher threshold motor units $(2,750$,
$2,100,2,000 \mu \mathrm{V})$ were $13-16$ times the respective largest unit potential near threshold.

An example in a healthy male 21 years old is shown in Figs 5 and 6. The AUPS based on the first 13 all or nothing successive potential steps above motor threshold was $59 \mu \mathrm{V}$. On the assumption that this AUPS is representative of the motor unit population, the motor unit estimate is obtained simply by:

$$
\text { MUE }=\frac{20,750 \mu \mathrm{V} \text { (MCP) }}{59 \mu \mathrm{V} \text { (AUPS) }}=352
$$

Provided no motor units much larger in size, but of higher threshold, can be shown, the MUE 


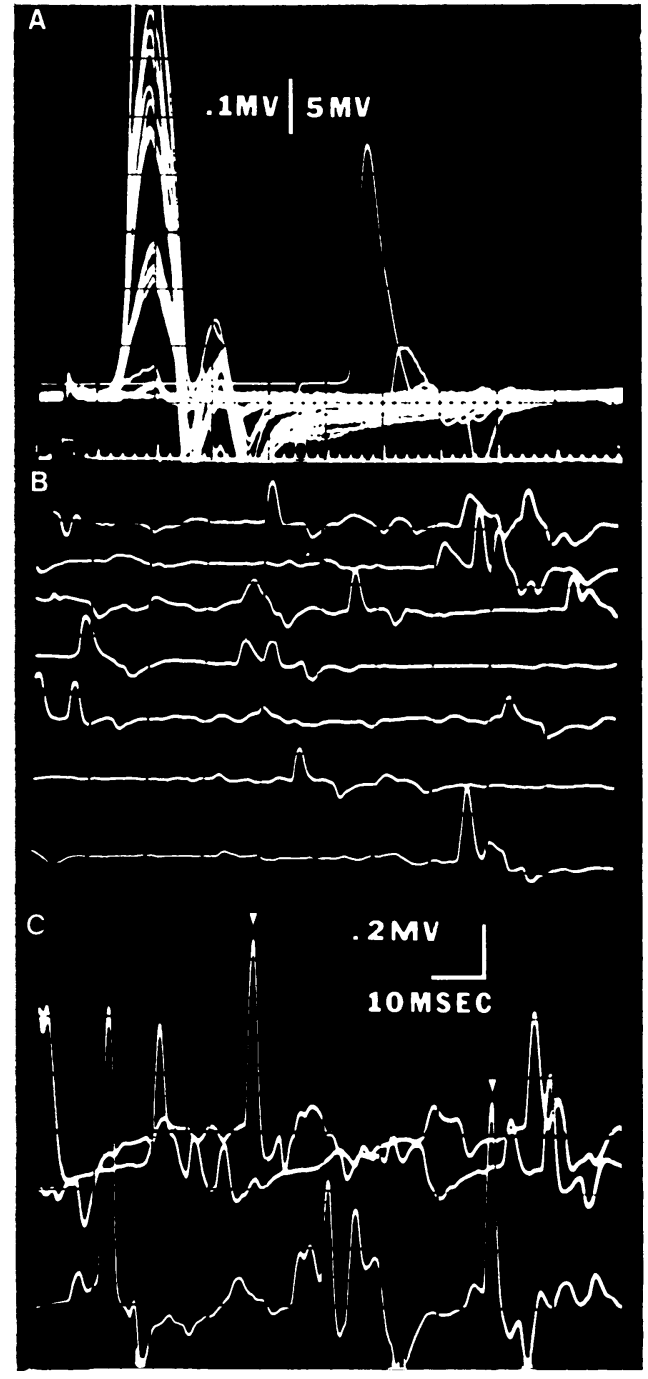

FIG. 5. Subject J.D. A. The first 11 MUPs (left) on which the AUPS was based and the MCP (right) from the thenar muscles. B. Small MUPs evoked with minimal voluntary activation and recorded with the same electrode arrangement as in A. C. Large motor units, some much larger than those upon which the AUPS was based, evoked by moderate voluntary activation. The unit marked with the arrow may be the same unit as unit b in Fig. 6.

based on this AUPS may be approximately correct. This was not the case. In this young man an increase in the stimulus intensity to the point at which the direct response was one-third of the maximum compound potential did evokeథ late discharge units of much larger size (Fig. 6 , C), the largest being $2,750 \mu \mathrm{V}$. The sum of the four largest units alone would account for almost $35 \%$ of the maximum direct response.

Each of the late discharge giant units in this@ subject which showed a variation in latency of less than $100 \mu$ s appeared at obviously different. thresholds. The discharge frequency of two of the four clearly defined giant late units dropped when the motor nerve stimulus was increased등 (Fig. 9). In most subjects, however, there was no significant change in the late response discharge frequency with a change in the stimulus intensityo above the appearance threshold of the unit.

The finding that late response single units of higher threshold could be much larger than $\vec{\omega}$ individual motor unit potentials excited near the? motor threshold was also shown in the EDB on? the hemiparetic side of a patient with infantilew hemiplegia (Fig. 7). In this patient, the largestio late response single unit first appeared at a motorio nerve stimulus close to the maximum. This la potential was 6.4 times the size of the larg度 unit potential $(282 \mu \mathrm{V})$ of the first six excited above the motor threshold and was one of fod single late response units which discharged independently and sometimes in combination (Fig. 4).

The late responses of 200 consecutive stimulit supramaximal for the direct response wereo delayed and examined on expanded sweeps (Fig. 4). It was obvious from comparing the area undero the curve of individual potential steps that theo potentials marked $E, F$, and $G$ represented in order, the sum of $\mathrm{A}+\mathrm{B}, \mathrm{B}+\mathrm{C}$, and $\mathrm{B}+\mathrm{D}$. If the discharge of each motor unit in the late response is independent of the discharge of other motor units, the frequency of discharge of the com pound potential should equal the product of the discharge frequencies of the component sub-o units. For example, the observed discharge fre quencies of potentials $\mathrm{A}, \mathrm{B}$ and the compoundô potential $E$ were: $F_{A}=2 \cdot 5 \%, F_{B}=22 \cdot 5^{\circ} \%$, and $F_{E}=1.5 \%$. The expected frequency of the com- 음 pound potential $F_{E}$ would be $F_{A} \times F_{B}=0.56^{\circ}$ ? This did not differ significantly from the observed $F_{E}$. Similarly, for compound potentials $F_{\sigma}$ and $G$, the observed and expected frequenciesin were not significantly different. In fact, for all of the single giant late response units in this studyo 
TABLE

CLINICAL DETAILS

\begin{tabular}{|c|c|c|c|c|c|c|c|c|c|c|c|}
\hline $\begin{array}{l}\text { Sub- } \\
\text { :ect }\end{array}$ & $\begin{array}{l}\text { Age } \\
(y r)\end{array}$ & Disease & Muscle & $M U E$ & $\begin{array}{l}\text { Units } \\
\text { used } \\
\text { to } \\
\text { derive } \\
\text { AUPS } \\
\text { (no.) }\end{array}$ & 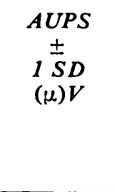 & Range & $\begin{array}{c}\text { Largest } \\
\text { late } \\
\text { response } \\
\text { single } \\
\text { units } \\
(\mu V)\end{array}$ & $\begin{array}{c}\text { Late } \\
\text { units } \\
\text { iso- } \\
\text { lated } \\
\text { (no.) }\end{array}$ & $\begin{array}{c}\text { Largest } \\
\text { late } \\
\text { unit/ } \\
\text { largest } \\
\text { direct } \\
\text { unit }\end{array}$ & $\begin{array}{c}\text { Direct } \\
\text { response } \\
\text { due to } \\
4 \text { (or less) } \\
\text { largest } \\
\text { late units } \\
(\%)\end{array}$ \\
\hline G.M. & 29 & Normal & Thenar & 417 & 11 & $43 \pm 40$ & $6-120$ & $\begin{array}{r}2,000,1,600 \\
1,140,900\end{array}$ & 29 & $16 \cdot 7$ & 31 \\
\hline M.K. & 33 & Normal & Thenar & 236 & 15 & $46 \pm 35$ & $8-107$ & $\begin{array}{c}1,020,680 \\
640,340\end{array}$ & 31 & $9 \cdot 5$ & 25 \\
\hline J.D. & 21 & Normal & Thenar & 352 & 11 & $59 \pm 61$ & $10-206$ & $\begin{array}{r}2,750,2,100 \\
1,750,800\end{array}$ & 6 & $13 \cdot 3$ & 35 \\
\hline D.H. & 25 & Normal & Thenar & 437 & 13 & $38 \pm 61$ & $12-235$ & $\begin{array}{c}1,490,1,260 \\
420,340\end{array}$ & 4 & $6 \cdot 3$ & 21 \\
\hline D.G. & 22 & Normal & EDB & 189 & 7 & $80 \pm 73$ & $12-218$ & 600,410 & 2 & $2 \cdot 8$ & 7 \\
\hline P.M. & 17 & $\begin{array}{l}\text { Myotonic } \\
\text { dystrophy }\end{array}$ & Thenar & 260 & 9 & $54 \pm 50$ & $18-153$ & $\begin{array}{c}540,200 \\
140\end{array}$ & 3 & $3 \cdot 5$ & 6 \\
\hline R.K. & 30 & $\begin{array}{l}\text { Guillain- } \\
\text { Barré } \\
\text { neuropathy }\end{array}$ & Thenar & 87 & 10 & $59 \pm 30$ & 24-120 & $\begin{array}{l}630,600 \\
\quad 410,130\end{array}$ & 4 & $6 \cdot 1$ & 34 \\
\hline B.P. & 49 & $\begin{array}{l}\text { Diabetic } \\
\text { neuropathy }\end{array}$ & Thenar & 203 & 7 & $93 \pm 93$ & $24-247$ & $\begin{array}{l}530,345 \\
320\end{array}$ & 3 & $2 \cdot 1$ & 6 \\
\hline D.B. & 30 & $\begin{array}{l}\text { Porphyric } \\
\text { neuropathy }\end{array}$ & Thenar & 36 & 7 & $184 \pm 197$ & 40-600 & $\begin{array}{l}530,350 \\
300,220\end{array}$ & 4 & 0.9 & 21 \\
\hline J.L. & 26 & $\begin{array}{l}\text { Infantile } \\
\text { hemiplegia* }\end{array}$ & EDB & 48 & 6 & $200 \pm 66$ & $94-282$ & $\begin{array}{r}1,800,780 \\
380,380\end{array}$ & 4 & $6 \cdot 4$ & 35 \\
\hline
\end{tabular}

* Affected limb.

no subunits of sufficient size or discharge frequency, or both, were found to account for the large potentials.

In seven of the 10 subjects, at least four large late response units were isolated, the sum of which would account for more than $20 \%$ of the maximum compound potential in each of these subjects.

The largest unit potentials in the late response were found in the normal subjects and the one patient with infantile hemiplegia. Only one, the patient with porphyric neuropathy, had no higher threshold late response units larger than any unit near threshold on which the AUPS was based. The ratio of the largest late response single units to the respective largest unit potential close to motor threshold was less in the patients with diabetic neuropathy, GuillainBarré neuropathy, and myotonic dystrophy than in the control subjects. This was not accounted for by the finding of very large single motor unit potentials just above the motor threshold.

It was possible to isolate the same late response unit with stimulation at two points of unequal distance from the muscle and thereby compare the afferent and efferent velocities of the response (Fig. 8). Each time, the conduction velocity in the two limbs was identical, which provided further evidence that the giant units were recurrent motor unit discharges and not a reflex response.

Other methods also evoked much larger units from EDB and the thenar muscles. Graded voluntary contraction of the EDB or the thenar muscles does excite larger units with additional effort (Fig. 5). This was true in normal and abnormal subjects. In fact, beyond the first five to 20 motor units evoked by voluntary action, it was common to find motor units many times the size of the first five to 20 excited by an electrical motor nerve stimulus above threshold.

There was no constant relationship between the latency and the potential size of the single unit late responses from EDB or the thenar muscles (Figs 4 and 6).

\section{DISCUSSION}

If the results of the present study are accepted, motor unit estimates based on an average unit 


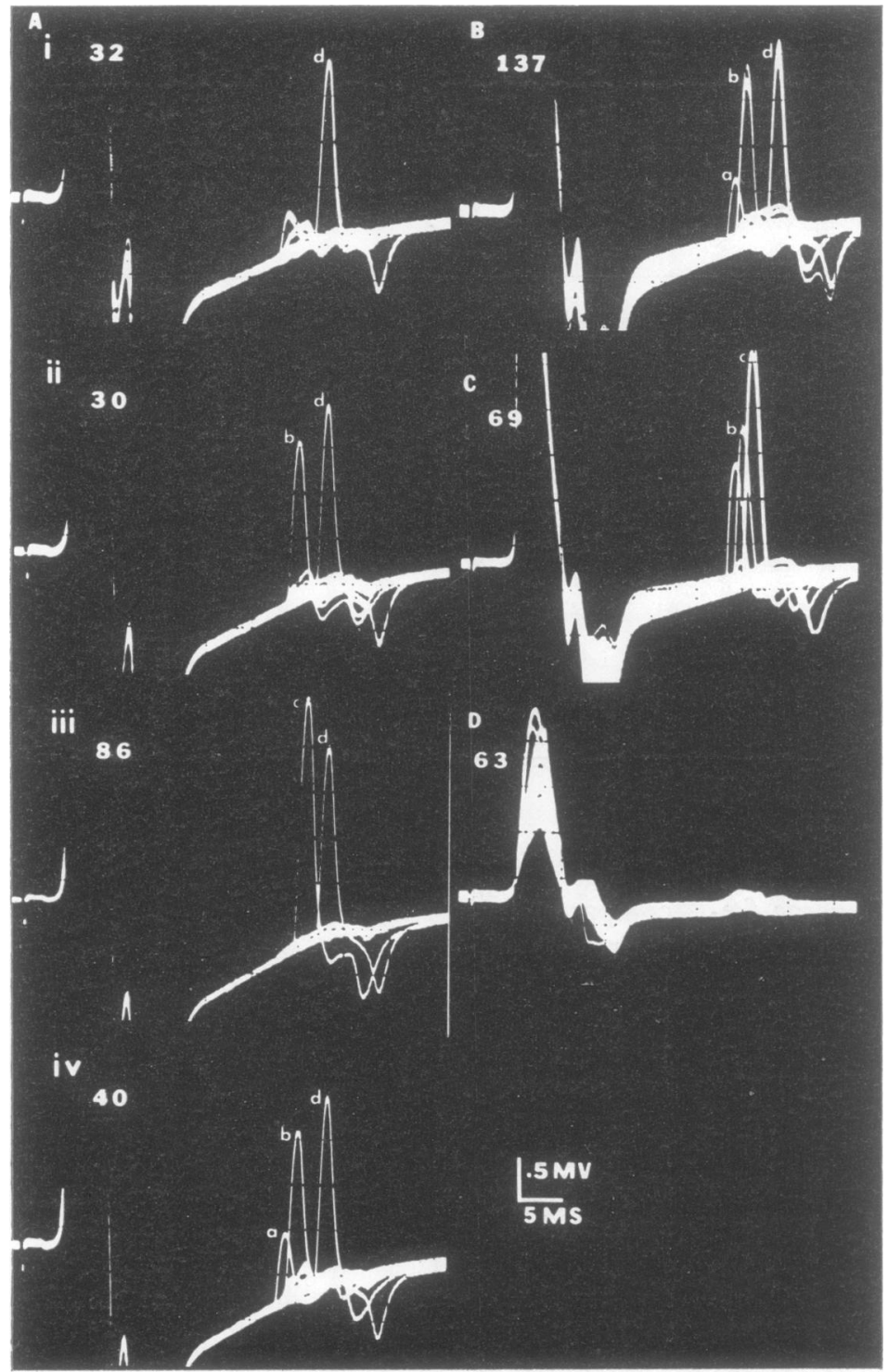

FIG. 6. Subject J.D. Thenar direct and late responses with the indicated number of traces superimposed. The traces shown in $\mathrm{Ai}-$ iv were consecutively recorded. The stimulus intensity in $\mathrm{D}$ was just above threshold and in $\mathrm{A}, \mathrm{B}$, and $\mathrm{C}$ evoked $100 \%, 66 \%$, and $33 \%$ of the MCP. The discharge frequency of each unit at each stimulus intensity is shown in Fig.

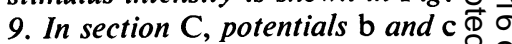
each occurred twice; in section $\mathrm{B}, \frac{\rho}{\mathrm{d}}$ a occurred once, $\mathrm{b}$ three times, anfo $\rightarrow$ $\mathrm{d}$ seven times; and in section $\mathrm{A}, \mathrm{a}$ occurred once, $\mathrm{b}$ three times, $\mathrm{c}$ once, and $\mathrm{d}$ six times.

potential size of the first few motor units excited above the motor threshold may not be valid. The evidence depends on whether the large late responses are in fact the potential discharge of single motor units or compound potentials. Provided the late responses accepted as single units were indeed single units, it matters little whether the late response was an $F$ response or a reflex discharge.
Are the criteria for a single unit justified? The fact that late response discharge frequency was low, makes it difficult to prove that late discharge units fire in an all or nothing fashion at a critical threshold. The finding of a critical threshold for the late discharge could not there- of fore be accepted as sufficient evidence alone for $N$ the late response being a single unit.

To limit the possibility that the giant late dis- 


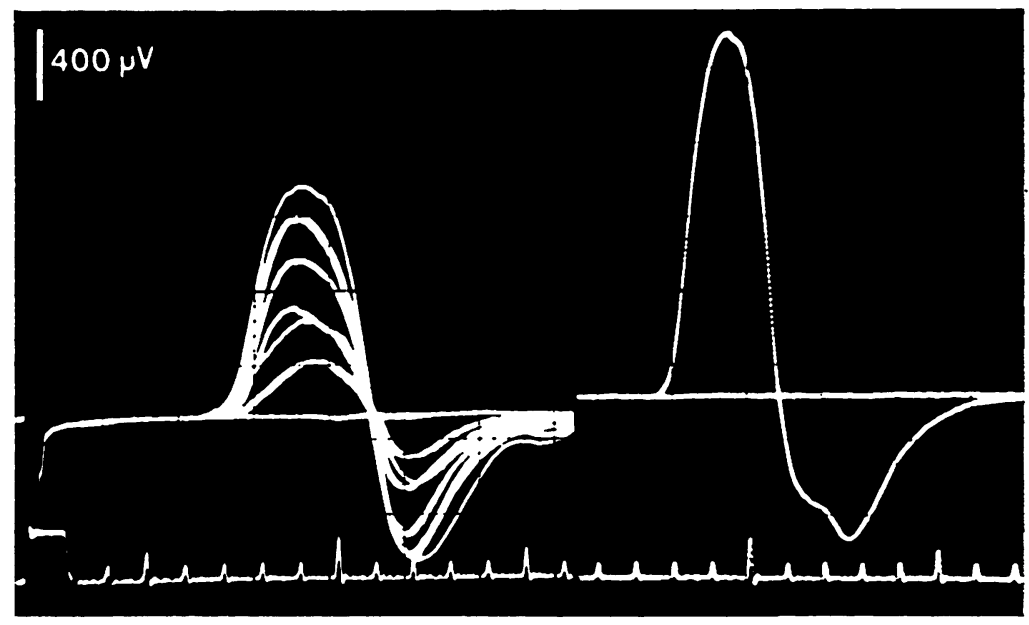

FIG. 7. Subject J.L. MUPs on which the AUPS was based (left) and the largest late response motor unit (delayed $43 \mathrm{~ms}$ ) evoked at maximum stimulus intensity. This late response unit is potential A of Fig. 4 and was 6.4 times the size of the largest measurable direct response unit.

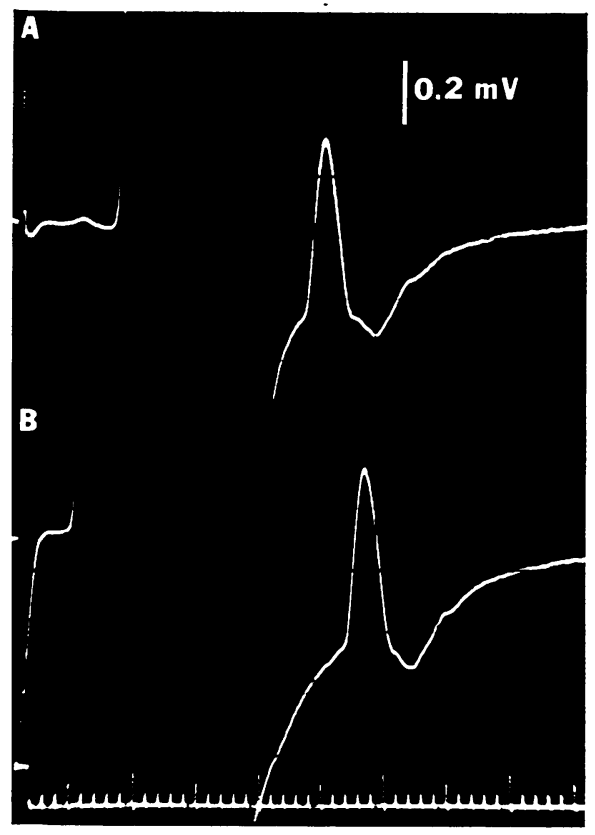

FIG. 8. The direct response and a single late response MUP from the thenar muscles. With stimulation of the median nerve at the wrist (B) and at the elbow (A), the direct response latency increased and the late response latency decreased by the same time interval, $3.3 \mathrm{~ms}$, indicating equal orthodromic and antidromic conduction velocities for the axon of this giant motor unit. charges were an $\mathrm{H}$ reflex discharge of more than one motor unit, only giant late discharges with a variation in latency of less than $100 \mu \mathrm{s}$ were chosen. Single $\mathrm{H}$ reflex motor unit discharges show a much greater variation in latency (Trontelj, 1973; Trontelj and Trontelj, 1973). It seems likely that an $\mathrm{H}$ reflex discharge of more than one motor unit would show an even greater variation in latency. Further evidence that the giant late discharges were not an $\mathrm{H}$ reflex was based on the findings that the antidromic and

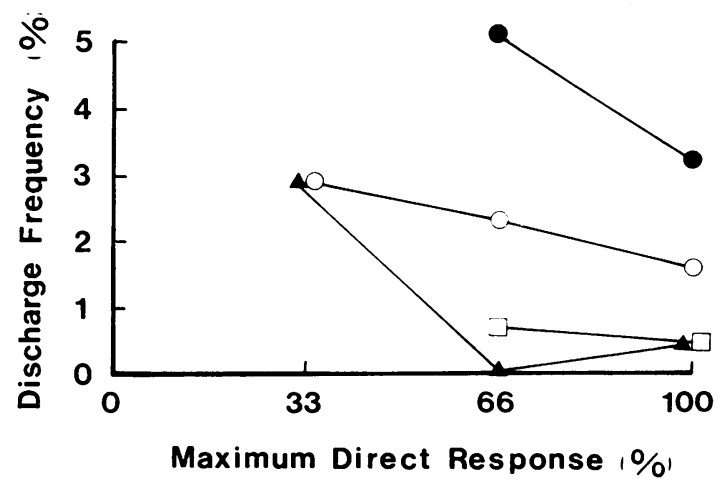

FIG. 9. The discharge frequencies of the four late response motor units isolated in Fig. 6 (J.D.) are shown at stimulus intensities evoking $33 \%, 66 \%$, and $100 \%$ of the MCP. Unit a: $\square$, unit $\mathrm{b}: \bigcirc$, unit $\mathrm{c}: \Delta$, and unit $\mathrm{d}: 0$. The decrease in discharge frequency of individual motor units with an increase in stimulus intensity was not seen in all subjects. 
orthodromic conduction velocities of individual units were identical and the fact that the giant units often first appeared well above the stimulus intensity at which the antidromic sensory potential was of maximum size. If the late discharges were not a reflex response they must have been either $F$ responses or axon reflexes. What of the possibility that some of the late response giant units were from axon reflexes? If so, the long latency of the discharge would require the branching to be far proximal, possibly as proximal as the nerve plexus or roots, or that the conduction velocity in the limbs of the axon reflex were much slower than other motor axons. Trontelj (1973) did find facial nerve axon reflexes with a latency that suggested branching in human ventral roots. Further, the conduction velocities of the limbs of the axon reflex usually differ (Stålberg and Trontelj, 1970; Trontelj and Trontelj, 1973), unlike the findings in the probable single unit late responses in this study. The low discharge frequency of probable single late discharge motor units was also unlike an axon reflex (Fullerton and Gilliatt, 1965; Stålberg and Trontelj, 1970; Trontelj and Trontelj, 1973).

Based on the above evidence it was probable that most or all of the giant late discharges were $F$ responses. The finding of no subunits large enough or with a high enough discharge frequency to account for the giant units reported in this study, made it unlikely that the giant units were the compound potentials of the recurrent discharge of more than one motoneurone. To be otherwise would require the synchronous recurrent discharge of a group of motoneurones of identical critical threshold, each of whose discharge was dependent on the discharge of the other motoneurones in the group. There is no evidence to date of the recurrent discharge of motoneurones being locked together in such a way.

The antidromic discharge of motor axons could influence the probability of back firing of individual motoneurones in two ways. First, the field potential produced by the antidromic volley could produce changes in the transmembrane potential of motoneurones. Eccles $e t$ al. (1954) found that the field potential produced little notable change in the motoneurone membrane potential, although a larger change at the initial segment cannot be excluded. Second, Renshaw cell excitation produced by the antidromic volley in motor axons could alter the excitability of motoneurones, particularly those with a slower motor axon conduction velocity to allow for the effect of the Renshaw discharge. Renshaw cell inhibition may well have accounted for the drop in discharge frequency of the large units with increased stimulus intensity found in one healthy subject.

It was perhaps surprising that no constant correlation was found between the latency of the late response single unit and the size of the unit. This finding was not expected because of the known correlation of conduction velocity with nerve fibre diameter and therefore, probably, motoneurone size. Even though there was some correlation between motor unit twitch tension and axon conduction velocity in cats (Wuerker et al., 1965) the link between twitch tension and conduction velocity in individual motor unitso was unpredictable. Further, no correlation wa용 found between motor unit twitch tension an $\Phi$ axon conduction velocity in the extensor digio torum communis of the baboon (Eccles et al 1968).

It might also be expected that large diamete fibres and therefore, large motor units, woul $\vec{\omega} \vec{\theta}$ have a lower threshold unlike the findings re ported here in which giant motor units were of much higher threshold than motor units with much smaller potential sizes. Factors other than diameter, however, influence the excitability of axons to percutaneous electrical stimulation (McComas et al., 1971). Although the motor units excited and the order of motor unit recruitment may differ with stimulation of the median or peroneal nerves at two or more points, the giant late response units never appeared close to the motor threshold except in some neuropathies.

If the giant unit potentials are single units and the corresponding motor fibres are indeed larger than other motor fibres, the higher thresholds must be explained by factors other than fibre size.

It seems likely therefore that, based on findings in this report, thenar and EDB motor unit populations do contain motor units of much $N$ larger potential size than those few close to the motor threshold on which the motor unit esti- 
mate AUPS is based. This means that motor unit estimates obtained to date may well overestimate the number of motor units.

It is difficult to compare the physiological estimates of motor unit numbers with estimates based on fibre counts in the lateral terminal branch of the anterior tibial nerve (McComas et al., 1971) and from the recurrent thenar motor branch (Lee and Ashby, 1973). In fact, the fibre count in the thenar motor branch of one 35 year old woman produced a motor fibre estimate (256) very close to the mean thenar motor unit estimate reported in this study.

The close identity of the anatomical and physiological estimates of thenar motor unit numbers is misleading. Both probably overestimate the number of motor units. Axon branching proximal to the most proximal section of the thenar motor branch used to estimate the number of motor axons could result in a substantial overestimate of the number of thenar motor units. Fibre counts in the thenar motor branch were obtained from sections no more proximal than $1 \mathrm{~cm}$ from the motor point of the thenar muscles (Lee, 1973). Motor axon branching very likely therefore contributed to the fibre count, because evidence of such branching was found as far as $22 \mathrm{~mm}$ proximal in the thenar motor branch of the baboon (Wray, 1969) and even more proximal in the posterior tibial nerve (Wray, 1969, Stålberg and Trontelj, 1970). Fibre counts in thenar motor axons would have to be obtained as much as $10 \mathrm{~cm}$ proximal to the thenar muscles before motor axon branching could be excluded as an important factor when the physiological and anatomical estimates are compared.

It is possible also, that motor units much smaller or more distant from the recording electrodes could be lost. The exclusion of such small units from the sample on which the average unit potential size is based, could partly compensate for the exclusion of the higher threshold giant units. The small size of the smallest motor unit potential steps (Table) was indeed very close to the noise level and it is clearly possible that units of this size or smaller could be missed.

In abnormal conditions, when all the normal motor unit potential steps could not be counted, it is possible that the estimate of motor unit loss was too high. A change in the order of activation of motor units with excitation of giant motor units at low threshold could bias the AUPS to a larger size and therefore make the motor unit estimate too low. It was common to find one or more giant motor units among the first five to 15 motor units evoked above the motor threshold in diabetics (Brown and Feasby, 1974). If only one such giant unit was found within the first few motor unit potential steps, the motor unit estimate was often normal or near normal. It was possible that a change in the normal activation order of motor axons accounted for the giant unit and not loss of motor axons with enlargement of one or several motor axons by collateral sprouting and terminal reinnervation.

Methods for estimating motor unit numbers have provided a very useful new technique for investigating disorders of the peripheral nerve and muscle. If the results of the present study are accepted, a better method must be chosen for choosing the sample population of motor units on which the AUPS is based.

The authors would like to acknowledge the valuable assistance of their neurological and neurosurgical colleagues who referred patients for the study, and Mrs M. Kaibara, Mr D. Hill, Mr J. Drake, and Mrs M. Webster.

\section{REFERENCES}

Brown, W. F. (1972). A method for estimating the number of motor units in thenar muscles and the changes in motor unit count with ageing. Journal of Neurology, Neurosurgery, and Psychiatry, 35, 845-852.

Brown, W. F. (1973). Functional compensation of human motor units in health and disease. Journal of Neurological Sciences, 20, 199-209.

Brown, W. F., and Feasby, T. E. (1974). Estimates of functional motor axon loss in diabetics. (Submitted for publication.) Journal of Neurological Sciences. (In press.)

Eccles, J. C., Fatt, P., and Koketsu, K. (1954). Cholinergic and inhibitory synapses in a pathway from motor-axon collaterals to motoneurones. Journal of Physiology, 126, 524-562.

Eccles, R. M., Phillips, C. G., and Chien-Ping, W. (1968). Motor innervation, motor unit organization and afferent innervation of $\mathrm{m}$. extensor digitorum communis of the baboon's forearm. Journal of Physiology, 198, 179-192.

Fullerton, P. M., and Gilliatt, R. W. (1965). Axon reflexes in human motor nerve fibres. Journal of Neurology, Neurosurgery, and Psychiatry, 28, 1-11.

Lee, R. G., and Ashby, P. (1973). A computer simulation of motor conduction in the median nerve. (Abstract.) Electroencephalography and Clinical Neurophysiology, 34 799.

Lee, R. G. (1973). Personal communication.

McComas, A. J., Fawcett, P. R. W., Campbell, M. J., and 
Sica, R. E. P. (1971). Electrophysiological estimation of the number of motor units within a human muscle. Journal of Neurology, Neurosurgery, and Psychiatry, 34, 121-131.

Milner-Brown, H. S., Stein, R. B., and Yemm, R. (1973). The orderly recruitment of human motor units during voluntary isometric contractions. Journal of Physiology, 230, 359-370.

Stålberg, E., and Trontelj, J. V. (1970). Demonstration of axon reflexes in human motor nerve fibres. Journal of Neurology, Neurosurgery, and Psychiatry, 33, 571-579.

Thorne, J. (1965). Central responses to electrical activation of the peripheral nerves supplying the intrinsic hand muscles. Journal of Neurology, Neurosurgery, and Psychiatry, 28, 482-495.
Trontelj, J. V. (1973). A study of the F response by single fibre electromyography. In New Developments in Electromyography and Clinical Neurophysiology, vol. 3, pp. 318322. Edited by J. E. Desmedt. Karger: Basel.

Trontelj, J. V., and Trontelj, M. (1973). F-responses of human facial muscles. A single motoneurone study. Journal of Neurological Sciences 20, 211-222.

Wray, S. H. (1969). Innervation ratios for large and small limb muscles in the baboon. Journal of Comparative Neurology, 137, 227-250.

Wuerker, R. B., McPhedran, A. M., and Henneman, E. (1965). Properties of motor units in a heterogeneous pale muscle (m. gastrocnemius) of the cat. Journal of Neurophysiology, 28, 85-99. 